\title{
ESTUDO DE USABILIDADE DO JOGO DIGITAL SOLITAIREQUIZ EM UM GRUPO DE IDOSOS
}

\section{USABILITY STUDY OF THE DIGITAL GAME SOLITAIREQUIZ IN A GROUP OF ELDERLY}

\author{
Ana Elisa Pillon ${ }^{1}$, M.Sc. \\ pillon.anaelisa@gmail.com https://orcid.org/0000-0002-7975-4694 \\ Bianca Antonio Gomes ${ }^{1}$, M.Sc. \\ biancaantonio@gmail.com https://orcid.org/0000-0003-3261-0383 \\ Bruna Andrade da Silva ${ }^{1}$, Esp. \\ brunaandrade1907@gmail.com https://orcid.org/0000-0002-5369-2069 \\ Vânia Ribas Ulbricht ${ }^{1}$, D. Sc. \\ vrulbricht@gmail.com https://orcid.org/0000-0002-6257-0557
}

\footnotetext{
${ }^{1}$ Universidade Federal de Santa Catarina, Programa de Pós Graduação em Engenharia e Gestão do Conhecimento, Florianópolis, Brasil
}

Idosos, Qualidade de vida, Usabilidade, Jogos Digitais

O crescente aumento do número de idosos no Brasil acaba gerando o crescimento de uma população com menos atividades laborais. Esse fator, coincidentemente com a expansão das tecnologias digitais de informação e comunicação, manifestou a necessidade de interfaces que facilitem o uso dessas ferramentas pelos idosos. Os jogos digitais surgem como uma opção cada vez mais utilizada para oferecer distração, diversão, saúde física e mental a este público idoso. Este artigo apresenta a análise da utilização do jogo SolitaireQuiz por cinco idosos entre 60 e 100 anos residentes em Florianópolis / SC. A pesquisa qualitativa foi utilizada como metodologia e como instrumentos de coleta, questionário e observação. Como resultado, percebeu-se que embora pudessem jogar, apenas um participante venceu o jogo e a maioria relatou ter dificuldade em entender as regras do jogo, bem como questões de visibilidade e regras, o pouco tempo de compreensão foi enfatizado. Para o futuro seria interessante buscar conhecer as sugestões dos participantes para melhorar o jogo. Ou, essa mesma pesquisa poderia ser conduzida em outros lugares, resultando em uma comparação de públicos idênticos, mas residentes em países diferentes.

\section{Elderly, Life Quality, Usability, Digital Games}

The increasing number of elderly in Brazil, ends up generating the growth of a population without work activities. Digital games are emerging as an option that is being used often to offer distraction, fun, physical and mental health to the elderly. This article presents the analysis of the use of SolitaireQuiz game by five elderly between 60 and 100 years. Qualitative research was used as a methodology, and the instruments for collection were questionnaire and observation. As a result, it was noticed that although the elderlies were able to play, only one participant won the game and most reported that they had difficulty understanding the rules of the game, emphasizing that they had little time to understand them. In future works could be relevant seek knowing the participants' suggestions in order to improve the game. Or, this same research could be performed in other countries, resulting in a comparison of identical but resident audiences in different countries. 


\section{Introdução}

A Organização Mundial da Saúde - OMS (2002), classifica como idosos pessoas com 60 anos ou mais apenas nos países em desenvolvimento, e altera essa designação nos países desenvolvidos para 65 anos ou mais. A escolha da idade cronológica para essa definição, parte do princípio que a partir dos 60 anos, no geral, as pessoas passam a ter problemas de saúde ocasionados pelo processo de envelhecimento. No entanto, o ritmo dos declínios apresentados por Sales (2002), de ordem fisiológica, sensorial, cognitiva e emocional ocasionados pelo envelhecimento, podem variar entre as pessoas.

A população brasileira com 65 anos de idade ou mais cresceu $26 \%$ entre 2012 e 2018 , ao passo que a população de até 13 anos recuou 6\%, conforme mostram dados da pesquisa "Características Gerais dos Domicílios e dos Moradores 2018", divulgada pelo Instituto Brasileiro de Geografia e Estatística - IBGE (IBGE, 2015). De acordo com dados deste instituto no ano de 2025, os idosos serão 34 milhões de pessoas, representando $15 \%$ da população brasileira. O aumento no número de idosos alerta para a forma como a população irá envelhecer, e a absorção dessas pessoas pela sociedade para que não se sintam inativas. (IBGE (2015).

Em relação a essa questão, Zanela, Bartholo Junior e Naveiro (2010) apontam que, com o aumento do número de idosos em escala mundial, evidencia-se a importância em aprimorar aspectos como a acessibilidade e usabilidade em produtos e sistemas desenvolvidos para a terceira idade que, como as demais pessoas têm, cada vez mais, vivenciado a inserção das tecnologias em seu dia a dia. Os autores enfatizam, ainda, a necessidade em desenvolver uma interface de usuário que considere as limitações e características próprias desta grande parcela da população, de forma que eles possam desfrutar de todos os benefícios que a tecnologia pode lhes oferecer, sem se sentirem excluídos.

Os jogos digitais são tecnologias que podem ser aplicadas aos idosos de forma a potencializar esses benefícios. Eles têm a capacidade de promover bem-estar físico e saúde mental, além de oferecer diversão e distração aos idosos. (SANTOS; ISHITANI; NOBRE, 2013).

Tendo em vista o exposto, torna-se vital novos estudos que possam identificar de que forma os jogos digitais podem contribuir para o aprimoramento da qualidade de vida destes usuários idosos. Em comentário a esta questão Cota, Vieira Junior e Ishitani (2015) salientam que os jogos digitais são capazes de oferecer diferentes possibilidades de estímulos e, com isso, melhorar a qualidade de vida destes usuários.

O projeto Connect-Play, desenvolvido no Canadá (AGE-WELL, 2019), visa pesquisar jogos sociais digitais para aprendizagem e entretenimento, e ocorre com o financiamento da Age-Well NCE, um órgão dedicado à criação de tecnologias e serviços para o benefício dos idosos e seus dependentes. Esse projeto tem como objetivo criar, estudar e comercializar jogos educacionais digitais que melhoram a qualidade de vida de idosos. Focados em identificar os critérios de usabilidade de um jogo educacional on-line e medir o grau de ergonomia de um jogo educacional em termos de design, usabilidade e legibilidade pedagógica, desenvolveram um jogo denominado SolitaireQuiz. (MENDOZA; SAUVÉ; PLANTE, 2017). A Figura 1 mostra uma imagem da tela inicial de jogo. 


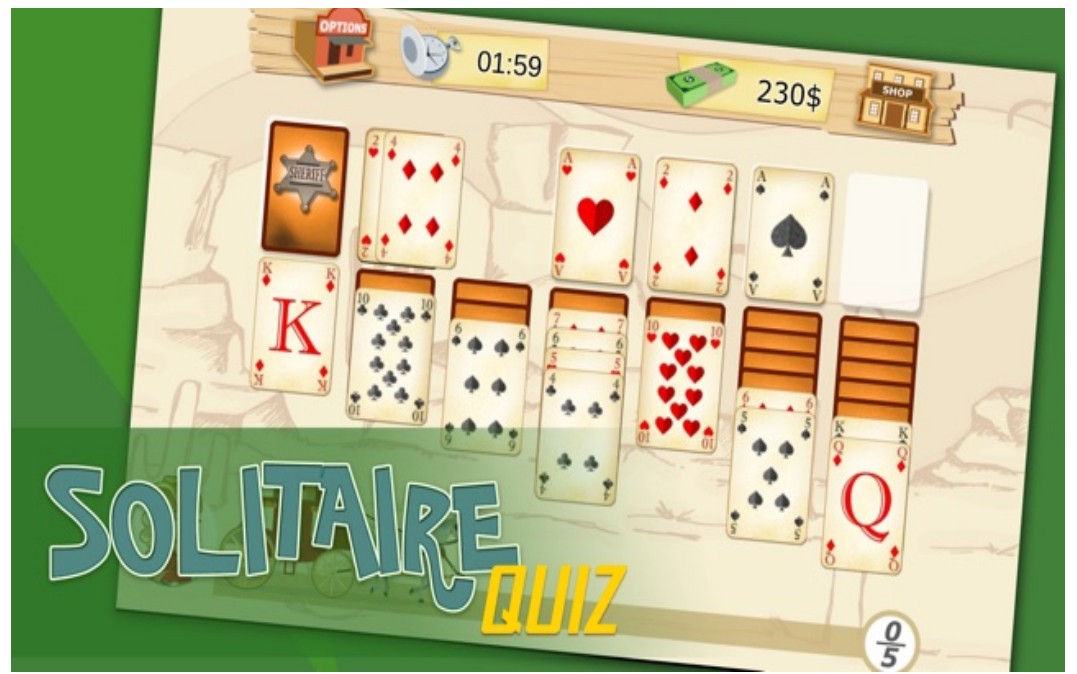

Figura 1 - Tela inicial do jogo. Fonte: Print Screen do jogo.

Neste trabalho o jogo SolitaireQuiz foi escolhido como objeto de estudo. Ele é um jogo digital no estilo paciência, onde o jogador deve formar grupos de cartas ordenados por números e cores, em ordem decrescente e, à medida que o usuário vai acertando a ordenação das cartas, uma pergunta sobre um tema escolhido inicialmente pelo usuário surge na tela. Caso o usuário acerte a pergunta ele recebe dinheiro para comprar itens que podem facilitar suas jogadas na "lojinha" do jogo, caso contrário o usuário perde uma certa quantidade de dinheiro.

Para que um jogo atenda aos interesses e as expectativas do usuário a quem ele se destina, é imprescindível que sejam consideradas as características culturais desse usuário, uma vez que as pessoas se identificam com o contexto no qual estão inseridas e se sentem bem. No entanto, essas características variam para diferentes grupos de pessoas e, desta forma, os jogos precisam ser projetados de formas diferentes para atender a essas diferenças culturais dos usuários. (DE SCHUTTER; ABEELE, 2010).

O jogo SolitaireQuiz foi inicialmente analisado no artigo intitulado Jogos Digitais para Idosos - uma experiência de ensino. (CORDEIRO; FADEL, 2019). Neste estudo, o jogo foi testado por 8 idosos e, em suas considerações finais, os autores destacaram a importância de realizar novos estudos com um grupo de participantes de diferentes culturas. Além disso, foi citada a relevância de observar os dados que poderiam vir a surgir ao se utilizar e avaliar o jogo em países e culturas distintas do Canadá, como por exemplo o Brasil. Diante desse cenário, o objetivo deste trabalho é investigar as percepções de idosos de Florianópolis/SC acerca da usabilidade do jogo SolitaireQuiz e, para tanto, foi formulada a seguinte questão de pesquisa para nortear este trabalho: Quais as percepções dos idosos de Florianópolis acerca da usabilidade do jogo SolitaireQuiz?

\section{Fundamentação teórica}

Leis, estatutos e até mesmo o senso comum constroem o que nós entendemos ser a figura do idoso. A Política Nacional do Idoso (PNI) - Lei no 8.842, de 4 de janeiro de 1994 (BRASIL, 1994) e o Estatuto do Idoso - Lei $\mathrm{n}^{\circ} 10.741$, de $1^{\circ}$ de outubro de 2003 (BRASIL; 2003) definem formalmente idosos como sendo pessoas com idade igual ou maior que 60 anos.

Hayflick (1996) e Papaléo Netto (2006), definem um idoso por meio do ritmo de envelhecimento biológico. A definição é baseada em alterações de aparência, peso, audição, visão, olfato, e falha de tecidos e órgãos. Neri (2007) corrobora com a definição de Hayflick (1996) e Papaléo Netto (2006), afirmando que os idosos 
são categorizados pela duração do seu ciclo de vida, sendo a última parte do ciclo delimitada por eventos de natureza múltipla, reguladas pela genética de cada pessoa, denominada velhice.

O fato é que o Brasil envelhece mais a cada ano pois, segundo o Instituto Brasileiro de Geografia e Estatística - IBGE (2015), a projeção da esperança ao nascer no ano 2000 era de 69,8 anos, contra 75,4 anos em 2015. No Brasil, a redução da mortalidade infantil, e o consequente aumento populacional, seguido do decréscimo da fecundidade nas últimas décadas, estão associados ao aumento do envelhecimento populacional, conforme afirma Camarano (2002).

De acordo com o IBGE (2015), no ano de 2025, os idosos serão 34 milhões de pessoas, representando 15\% da população brasileira. $\mathrm{O}$ aumento no número de idosos alerta para a forma como a população irá envelhecer, e a absorção dessas pessoas pela sociedade para que não se sintam inativas. Porto e Rezende (2016) definem o envelhecimento ativo como equilíbrio entre os aspectos biopsicossociais, integração dos indivíduos em um meio social e capacidade de desenvolver as próprias potencialidades.

Envelhecer ativamente exige a busca por uma melhor qualidade de vida, autonomia, maior exercício da capacidade funcional e ainda a manutenção ou ampliação das interações sociais. Nesse cenário, o uso das Tecnologias de Desenvolvimento da Informação e Comunicação (TDIC's) auxilia os idosos a se manterem ativos diante desse novo cenário de vida.

\subsection{A Tecnologia e os idosos}

A tecnologia, segundo Ferreira (2010, p. 650), significa: "Ciência cujo objeto é a aplicação do conhecimento técnico e científico para fins industriais e comerciais." Com base nesse conceito, podemos entender sinteticamente que a Tecnologia de Desenvolvimento da Informação e Comunicação - TDIC refere-se a forma de comunicarmos informações por meio de tecnologias.

Como enfatiza Gonçalves (2012), a TDIC pode ser definida por um conjunto de recursos tecnológicos integrados, que oportunizam a automação e a comunicação de processos de negócios, pesquisas científicas e de ensino e aprendizagem, por meio de hardware, software e telecomunicações.

Os computadores, smartphones, tablets, e a internet são mecanismos que armazenam e comunicam a informação, ou seja, são TDICs. Para Brito (2012), essas tecnologias estão presentes na sociedade, e influenciam o tempo, espaço, a forma de agir, pensar e aprender. Essa interação resulta em pessoas interligadas que produzem e partilham conhecimentos e informações, tornando quem não tem acesso à tecnologia um infoexcluído.

Os idosos são um grupo da sociedade pretenso a se tornar infoexcluído, em sua maioria tiveram pouco ou nenhum contato com ferramentas de TDICs durante sua formação. Esse contexto histórico pode ser responsável pelo desconhecimento dessas ferramentas gerando uma falta de interatividade entre os idosos e as TDICs.

Estudos realizados por Ansley e Erber (1988) e McMellon e Schiffman (2002), verificaram que os idosos são receptivos à utilização das TDICs, embora possam ser mais lentos que os jovens nesse processo de aprendizagem, conforme também assinala Tompowrski (2003). Pirola, Velho e Vermelho (2012) corroboram com a afirmação de que os idosos querem estar atualizados por meio das tecnologias e, com isso, se sentirem mais independentes e socialmente envolvidos.

Rocha e Padovani (2017) salientam que as pessoas de 60 anos ou mais têm tentado incluir smartphones para a realização de diferentes tarefas no seu cotidiano. Ressaltam, no entanto que, embora os fabricantes estejam atentos à tendência do aumento da utilização de smartphones por essa parte da população que vem aumentando exacerbadamente, ainda afirmam que a configuração da interface dos mesmos não foi pensada para este público alvo, comprometendo, desta forma, o uso satisfatório destes dispositivos móveis por eles. 
O direito de utilização das TDICs pelos idosos é assegurado pelo Estatuto do Idoso, Lei $\mathrm{n}^{\circ} 10.741$, de $1^{\circ}$ de outubro de 2003, onde além de instituir o direito à educação, cultura, esporte, lazer, diversões, espetáculos, produtos e serviços que respeitem sua peculiar condição de idade, a legislação acrescenta o direito a cursos especiais relacionados aos avanços tecnológicos. (BRASIL, 2003).

A redução dos aspectos sensoriais, cognitivos e funcionais, resultantes do processo de envelhecimento, aumentam a dificuldade da relação entre os idosos e a tecnologia. Um fator relevante e contributivo para esse problema é a falta de interfaces voltadas especificamente para esse nicho, sendo que o processo de envelhecimento coloca o indivíduo no entremeio do usuário convencional e o usuário com necessidades especiais.

Conforme reforçam Zanela, Bartholo Junior e Naveiro (2010), a usabilidade, a facilidade do uso e a aprendizagem do sistema são requisitos essenciais no desenvolvimento de projetos de tecnologia voltados aos idosos. Os benefícios gerados aos idosos pelo uso da tecnologia apresentados por Filizola e Rose (2007), como facilitação no processo de comunicação, estimulação da interação social e redução do isolamento, só serão obtidos caso exista interação entre a tecnologia e o usuário.

\subsection{Os Jogos digitais e os idosos}

A definição de jogo é bastante ampla e variada, no entanto muitos autores relacionam a definição de jogo à atividade livre, lúdica, consciente, sem intenção de lucro e exterior à vida cotidiana. Absorvendo o jogador de maneira intensa, algumas das características inerentes ao jogo são a repetição, a linguagem própria e a possibilidade de escolha. (PIRES; GUILHEM; GOTTEMS, 2013).

De acordo com Zimmerman (2004) jogo é uma atividade voluntária com participação explícita do jogador (atividade interativa) na qual um ou mais jogadores seguem regras e, onde há um conflito artificial que termina em um resultado quantificável. Existem diversos tipos de jogos - jogos de computador, jogos de tabuleiros, jogos de cartas, jogos infantis - bem como diversas formas de se jogá-los e todos esses jogos se referem a objetos diferentes. (Zimmerman, 2004). Em português a palavra jogo pode abranger todos esses objetos diferentes, porém na língua inglesa, se utiliza a palavra game para se referir a jogos digitais.

Santos, Ishitani e Nobre (2013, p. 26) afirmam que usabilidade "é considerada pela ISO/IEC 9126 como uma das características para qualidade do software, sendo definida como a capacidade do software ser entendido, aprendido e usado, e também a capacidade de utilização em condições específicas". A usabilidade, desta forma, é um elemento de grande importância quando se trata de jogos, uma vez que minimiza as dificuldades de interação dos usuários com a interface. (SANTOS; ISHITANI; NOBRE, 2013).

Usabilidade significa facilidade de uso, e está relacionada ao uso eficiente de um produto interativo. (TAMBASCIA et al., 2008). Os autores afirmam ainda que o elemento primário no conceito de usabilidade é a noção de realização de uma tarefa pelo usuário - sendo formada pela realização de um número finito de passos durante certo tempo. Assim, durante uma sessão de avaliação de usabilidade o usuário deverá executar algumas tarefas.

Dado o exposto, cabe ressaltar a importância da facilidade do uso em jogos digitais, para que os usuários, independente da sua idade ou limitação, possam sentir prazer na introdução deste tipo de tecnologia em seu cotidiano, possibilitando assim a sua imersão no mundo digital e possível ampliação dos seus contatos, sejam físicos ou virtuais.

Nielsen (1993), afirma que a usabilidade está associada com o uso da interface de um software, a facilidade de aprendizado dessa interface e a satisfação do usuário ao utilizar essa interface. $\mathrm{O}$ autor complementa ainda que usabilidade possui cinco componentes principais, apresentados abaixo: 
1. Facilidade de aprendizado: o sistema deve ser fácil de aprender a ponto de permitir que um usuário sem experiência consiga o compreender rapidamente e imediatamente obtenha resultados;

2. Eficiência de uso: uma vez que o usuário aprenda como utilizar o sistema, ele tenha um alto nível de produtividade;

3. Facilidade de memorização: as interfaces devem ser fáceis de serem lembradas, os usuários que retornarem após certo tempo devem saber como utilizar o sistema sem que seja necessário refazer todo o processo de aprendizado;

4. Minimização de erros: a quantidade de erros apresentados pelo sistema deve ser a menor possível e, se erros ocorrerem, o sistema deve oferecer soluções simples e rápidas para resolvê-los;

5. Satisfação subjetiva: uso do sistema deve ser agradável ao usuário, e não deve frustrar o usuário enquanto este o utiliza.

Quando entramos no contexto dos jogos digitais a usabilidade recebe algumas definições extras. Conforme apontam Viana, Salgado e Trevisan (2017, p. 158): ela "age sobre a interface e engloba os elementos de interação com o jogo (controle, mouse e teclado etc) (...). É a medida na qual um jogador é capaz de aprender, controlar e entender um jogo".

A sociedade atual convive diariamente com aparatos tecnológicos hoje imprescindíveis à nossa sobrevivência. São aparelhos eletroeletrônicos, computadores, celulares e outros tantos equipamentos que nos auxiliam na manutenção das nossas atividades diárias, pessoais, profissionais ou sociais, seja para nos deslocarmos, mantermos contato com a família e amigos ou, ainda, resgatar nossos valores em bancos eletrônicos. No entanto, Carmo (2016) salienta que esta adaptação à tecnologia nem sempre é bem vinda pelas pessoas idosas, que têm certa dificuldade em acompanhar o ritmo de exigências para a utilização dos aparelhos cada vez mais modernos e sofisticados.

\section{Metodologia}

A fim de responder à questão problema deste estudo, foi utilizada uma abordagem de cunho qualitativo, uma vez que o mundo real e o sujeito possuem um vínculo indissociável entre o objetivo e a subjetividade do sujeito. De modo geral, a pesquisa qualitativa é composta pela interpretação e atribuição de significados dos fenômenos do mundo real. (GIL, 2008).

A pesquisa tem um elemento fundamental: a observação, que desempenha um papel crucial no processo de pesquisa, desde a formulação do problema, passando pela construção de hipóteses, até a coleta, análise e interpretação dos dados. Tendo, contudo, um papel mais evidente na fase de coleta de dados. (GIL, 2008). A observação é muito útil para obter informações, além de ser possível, com o seu uso, constatar comportamentos. (PRODANOV; FREITAS, 2013).

O NETI - Núcleo de Estudos da Terceira Idade é um núcleo pertencente à Pró-reitoria de Extensão da Universidade Federal de Santa Catarina - UFSC que faz parte do esforço nacional em prol do envelhecimento sadio. (NETI, 2020). Os sujeitos que participaram desta pesquisa eram alunos idosos do NETI, com idade entre 60 e 100 anos, sendo que todos participaram voluntariamente e assinaram o Termo de Consentimento Livre e Esclarecido - TCLE, autorizando o uso de imagem, voz e som. A pesquisa foi realizada com cinco idosos.

A coleta de dados ocorreu através de dois instrumentos: a observação e o questionário. Cada idoso foi conduzido separadamente a uma sala, e direcionado até o notebook onde o jogo SolitaireQuiz já estava disponível. A pesquisa foi realizada com a presença de três pesquisadores. Dois pesquisadores realizaram a observação, enquanto um dos pesquisadores foi responsável por esclarecer aos idosos participantes as informações gerais sobre a pesquisa, coletar a assinatura do TCLE, e apresentar o roteiro de tarefas 
constituído de sete atividades que foram executadas pelo idoso durante o período de interação com o jogo SolitaireQuiz. Estas tarefas foram: 1. Escolha o idioma do jogo; 2. Crie sua conta e entre no jogo; 3. Escolha o tema para jogar; 4. Escolha a quantidade de cartas; 5. Selecione o nível de dificuldade e inicie a primeira partida; 6. Jogue por cerca de 10 minutos; 7 . Compre 1 item de $75 \$$ ou $150 \$$ na loja; 8 . Clique na "Vaqueira" e leia as instruções; 9. Inicie uma nova partida.

Após o cadastro, escolha do tema, e da quantidade de cartas, cada idoso teve dez minutos para jogar o game SolitaireQuiz e, após esse período, em uma segunda etapa, foi entregue um questionário estruturado composto por perguntas fechadas e abertas por intermédio do qual os idosos puderam explanar suas percepções sobre o jogo digital.

A Figura 2 mostra alguns dos participantes durante a primeira etapa.

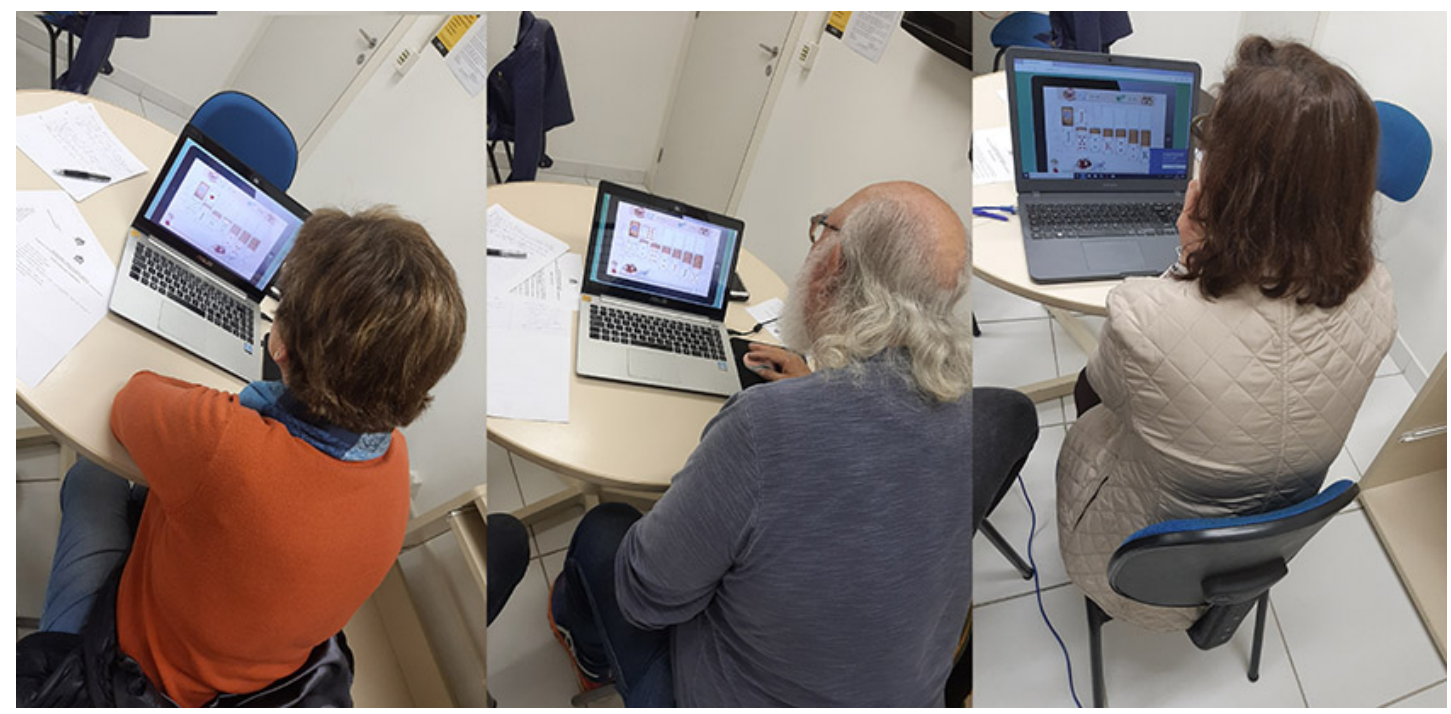

Figura 2 - Participantes jogando SolitaireQuiz. Fonte: As autoras (2020).

Durante o período de análise, os pesquisadores observaram os idosos jogando e realizaram suas anotações embasados por um roteiro de observação composto por sete apontamentos: 1. Os sujeitos compreenderam a operacionalização da tela de seleção de temas? 2. Os participantes puderam jogar sem dificuldade? 3. Os sujeitos entenderam que poderiam escolher as cartas, mover as cartas e organizar elas por naipes? 4. Os participantes conseguiram usar o menu de ajuda, o menu de opções e o menu de compra? 5. Os sujeitos conseguiram responder as questões em relação ao nível escolhido (fácil, médio, difícil)? 6. Eles perceberam que a cada acerto a carroça torna-se um objeto animado e anda? Além disso, eles perceberam que se ela "andar" um certo número de vezes, surge uma pergunta sobre o tema escolhido? E eles perceberam que se eles acertarem a resposta, eles ganharão dinheiro? 7. Os sujeitos se divertiram durante as brincadeiras?

Após a etapa em que os idosos finalizaram o tempo do jogo SolitaireQuiz passou-se à fase de preenchimento do questionário avaliativo. Na Figura 3 apresenta-se o mesmo. 


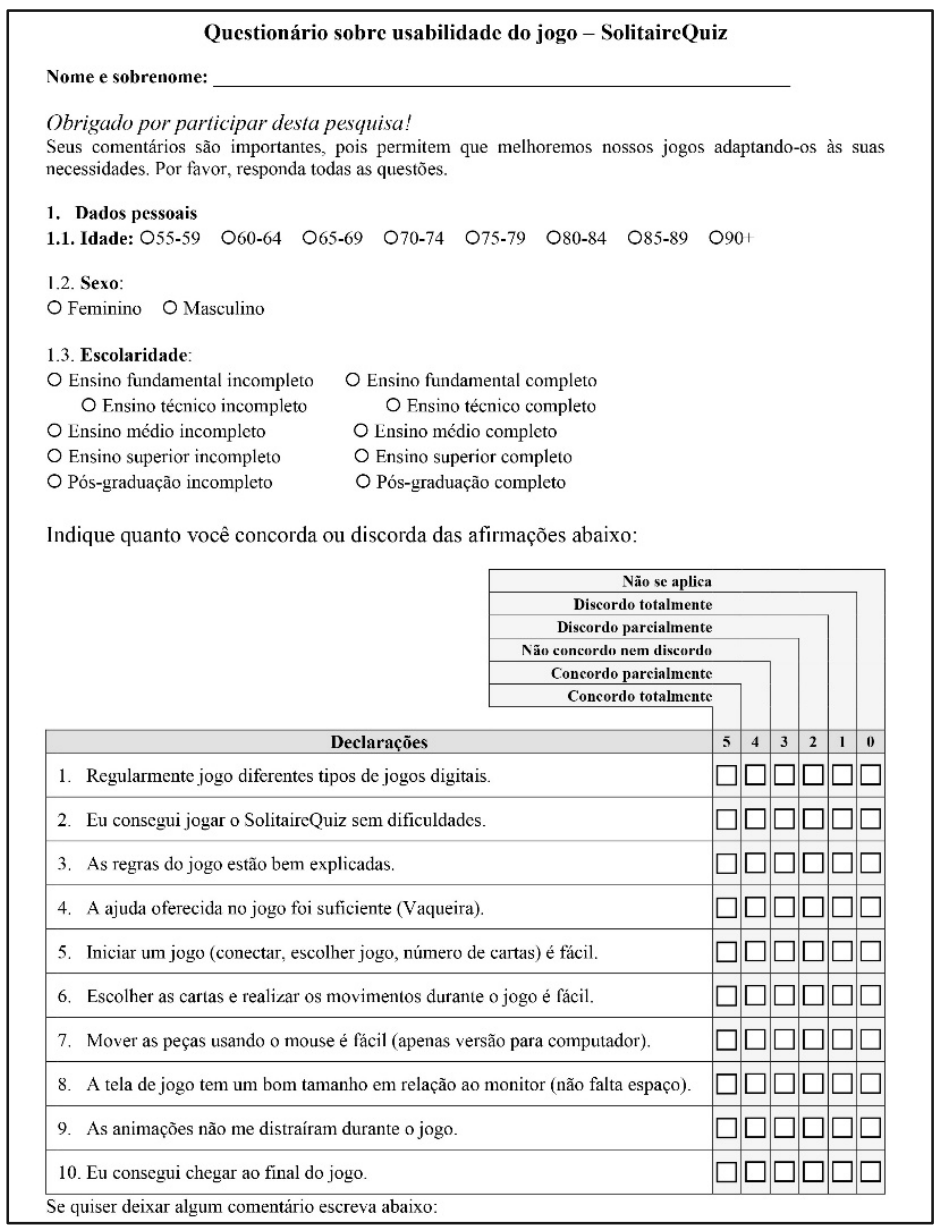

Figura 3 - Questionário avaliativo aplicado aos idosos. Fonte: As autoras (2020).

As principais reflexões dos pesquisadores quanto à observação dos idosos jogando assim como suas respostas ao questionário serão apresentadas no tópico seguinte.

\section{Resultados}

O escopo definido para a pesquisa foi um grupo de idosos com idade entre 60 e 100 anos, alunos do NETI. No início do questionário haviam perguntas sobre dados pessoais dos sujeitos - idade, sexo e escolaridade. No que se refere ao quesito idade, percebeu-se que, participaram desse estudo idosos de idade entre 60 e 74 anos. Quanto ao sexo, as mulheres corresponderam a $60 \%$ dos entrevistados, enquanto, os homens representaram $40 \%$. Em relação à escolaridade, $60 \%$ dos entrevistados concluíram o ensino superior e $40 \%$ ingressaram porém não completaram este mesmo ciclo de ensino.

Na sequência, o questionário continha dez perguntas fechadas com seis alternativas de resposta: discordo totalmente, discordo parcialmente, não concordo nem discordo, concordo parcialmente, concordo totalmente e não se aplica. A primeira pergunta questionava se os sujeitos jogavam diferentes tipos de jogos digitais, no entanto, apenas $20 \%$ concordaram totalmente com a afirmação, ou seja, apenas um sujeito jogava regularmente enquanto que o resto, $60 \%$, demonstraram não ocuparem seu tempo com a prática de jogos digitais. 
Na segunda questão o sujeito deveria usar as alternativas para julgar a seguinte alternativa: "Eu consegui jogar o SolitaireQuiz sem dificuldades", aqui $20 \%$ dos idosos, um sujeito, concordou totalmente com a afirmação, sendo o mesmo que respondeu que possuía prática com jogos digitais. O Gráfico 1 ilustra as respostas dos sujeitos.

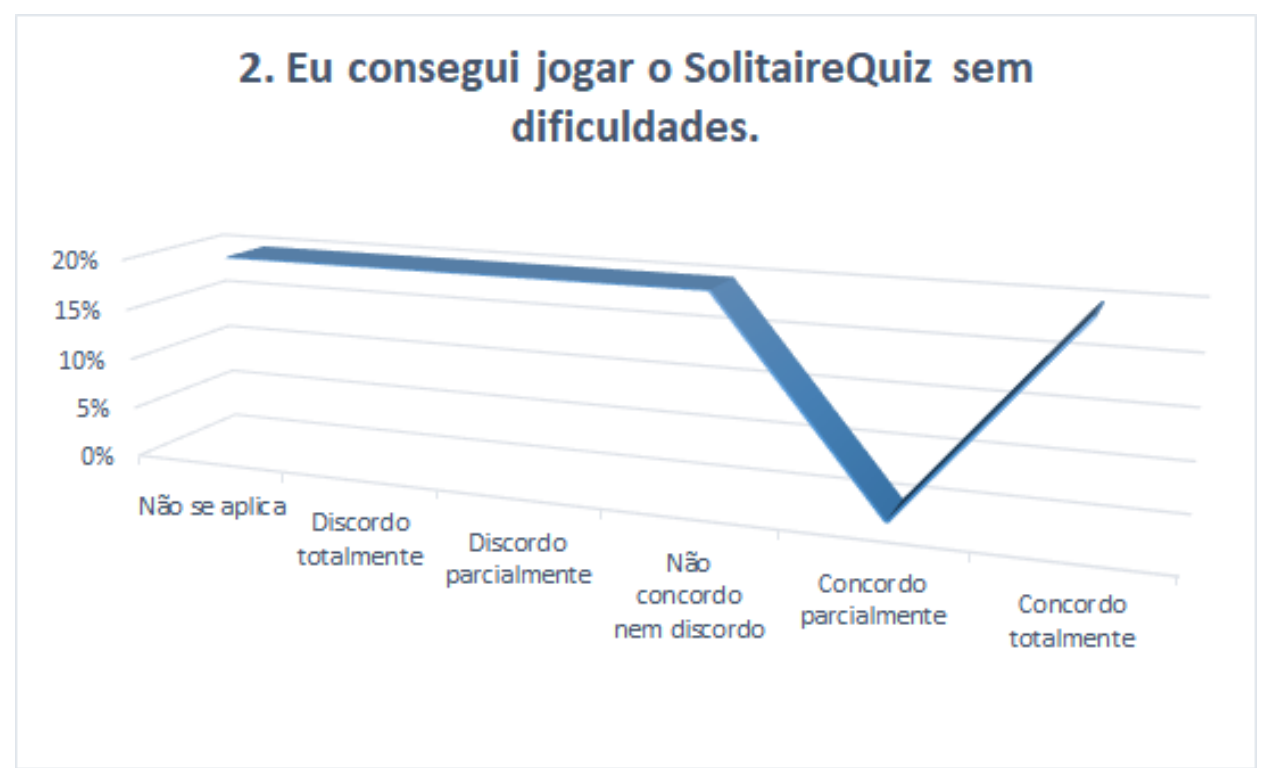

Gráfico 1 - Respostas à segunda pergunta do questionário. Fonte: As autoras (2020).

A partir da observação do Gráfico 1 e relato deste participante - o único que assinalou "concordo totalmente" na resposta 2 , infere-se que a prática regular dos jogos pode ter ajudado este sujeito a entender melhor o jogo. Uma vez que o jogo pode ser usado como ferramenta de exercício mental (CHEN et al., 2012), pode-se deduzir, desta forma, que, devido a esse fator, é possível que esse sujeito possua um raciocínio cognitivo e lógico mais desenvolvido em relação a jogos do que os outros participantes. Buiza et al. (2009) complementam ainda que os efeitos relacionados às dificuldades cognitivas causadas pelo envelhecimento, como perda de memória e falta de atenção, podem ser reduzidos através do uso do jogo.

A etapa de observação dos idosos jogando foi realizada tendo em vista as sete questões norteadoras da observação. Durante este período, levando em conta os dois primeiros itens norteadores -1 . Os sujeitos compreenderam a operacionalização da tela de seleção de temas? 2. Os participantes puderam jogar sem dificuldade? - foi constatado que, embora a maioria dos sujeitos tenha afirmado que conseguiu jogar o SolitaireQuiz sem maiores dificuldades, os sujeitos tinham muita dificuldade em jogar. Ao sentarem na frente do computador, mesmo com a tela inicial do jogo já iniciada, e com o roteiro de tarefas a ser executado em suas mãos, eles não sabiam o que fazer e, então, foi necessário que os pesquisadores ajudassem os sujeitos e explicassem como fazer o cadastro e iniciar o jogo.

No que tange aos aspectos norteadores três e quatro - 3. Os sujeitos entenderam que poderiam escolher as cartas, mover as cartas e organizar elas por naipes? 4. Os participantes conseguiram usar o menu de ajuda, o menu de opções e o menu de compra? - sessenta por cento dos entrevistados afirmou no questionário que as regras do jogo estavam bem explicadas. Durante a observação, entretanto, foi possível verificar que quando solicitado o auxílio da "Vaqueira", clicando sobre ela no jogo, esta não supria a necessidade do usuário. Esta constatação pode ter ocorrido em parte, pelo fato da "Vaqueira" dar explicações prontas e, de outra parte, pela alta velocidade com que o texto transitava na tela, impossibilitando sua leitura e compreensão por parte dos usuários idosos. Na Figura 4 apresenta-se a ajuda da "Vaqueira". 


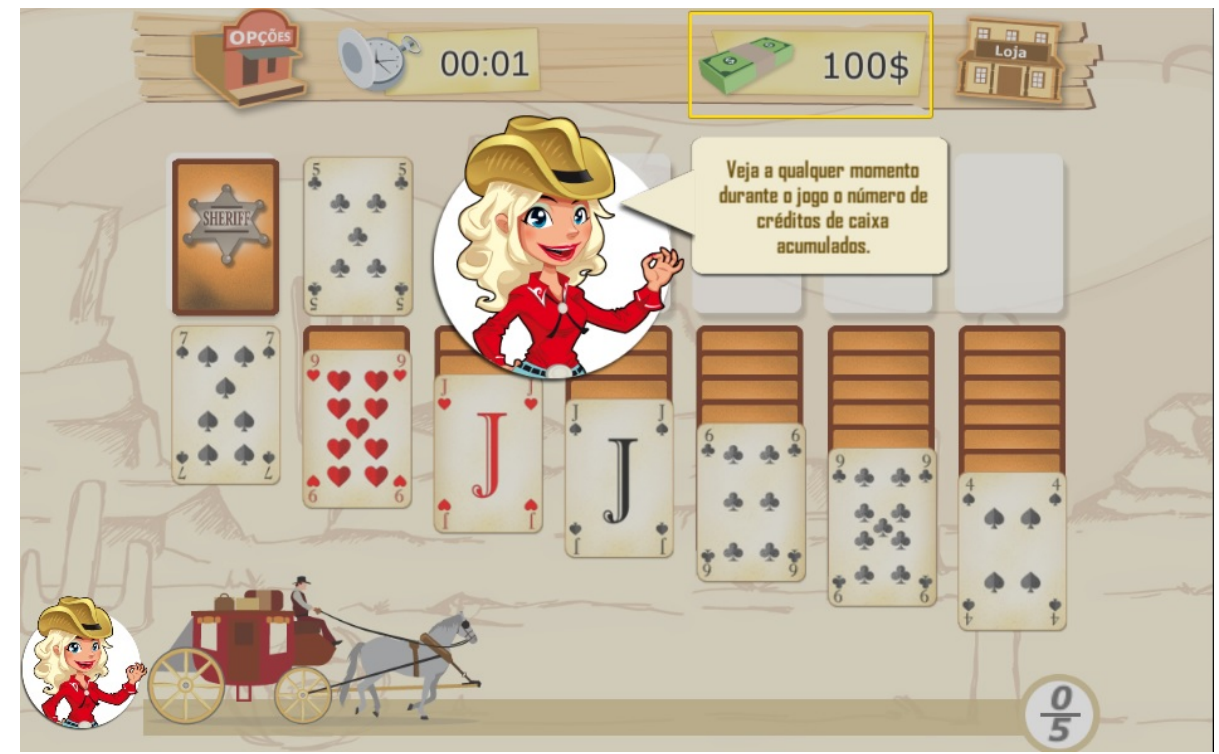

Figura 4 - Item de ajuda na tela do jogo - "Vaqueira". Fonte: Print Screen do jogo.

Iniciar um jogo, mover as peças utilizando o mouse foi considerado fácil, ou parcialmente fácil pelos idosos que participaram da pesquisa. Não foi observada dificuldade sobre o domínio do mouse para utilização do jogo SolitaireQuiz. Quanto à escolha das cartas e a realização de movimentos com elas durante o jogo, a maioria dos sujeitos, $60 \%$, disse que era fácil fazê-lo. Enquanto os outros 40 por cento ficaram divididos, entre discordar parcialmente da afirmação de que é fácil realizar as tarefas mencionadas e não concordar ou discordar da afirmação. No entanto, quando se considera a questão norteadora cinco -5 . Os sujeitos conseguiram responder as questões em relação ao nível escolhido (fácil, médio, difícil)? - pode-se observar que alguns idosos demonstraram dificuldades em entender a ordem das cartas e o sentido das cores.

No que se refere ao sexto item - 6. Eles perceberam que a cada acerto a carroça torna-se um objeto animado e anda? Além disso, eles perceberam que se ela "andar" um certo número de vezes, surge uma pergunta sobre o tema escolhido? E eles perceberam que se eles acertarem a resposta, eles ganharão dinheiro? compreendeu-se, através da observação, que os idosos não conseguiram associar o movimento da carroça ao surgimento de novas perguntas que, ao serem respondidas corretamente, lhes ofereciam recompensa no formato de dinheiro do jogo. Aponta-se ainda, que os usuários poderiam utilizar este dinheiro para trocar por benefícios que poderiam auxiliar o usuário a vencer o jogo.

Com relação à última questão norteadora da observação - 7. Os sujeitos se divertiram durante as brincadeiras? - observou-se que os sujeitos estavam divertindo-se durante o jogo, portanto, o jogo atingiu um de seus objetivos principais, o entretenimento.

Além dos aspectos citados acima, durante a observação notou-se ainda, problemas de acessibilidade no design do jogo. A relação do tamanho da tela do jogo e o monitor, e a não distração durante o jogo devido às animações, foram aprovadas plenamente pelos pesquisados. No entanto, o tamanho do número das cartas e o contraste de cores da tela dificultaram a visão por parte dos sujeitos. E apenas $20 \%$ dos idosos pesquisados conseguiram chegar ao final do jogo, ou seja, vencê-lo. Desta forma constatou-se que faltou certo cuidado em relação ao usuário no desenvolvimento da interface deste jogo, pois no desenvolvimento de um projeto de jogo para idosos, é sempre necessário levar em consideração diversos fatores que normalmente não são considerados para o público mais jovem, como redução da acuidade visual, redução do intervalo de acomodação visual, perda da sensibilidade ao contraste, diminuição da capacidade de adaptação da visão ao escuro e diminuição na sensibilidade à cor (COTA; VIEIRA JUNIOR; ISHITANI, 2015). Neste sentido, quando o desenvolvedor projeta um jogo para esse grupo em particular é inadequado a utilização de 
pequenas legendas, o posicionamento dos controles muito próximos uns dos outros ou apresentar informações espalhadas pela tela.

\section{Considerações finais}

Ainda que certos aspectos da usabilidade do jogo SolitaireQuiz tenham apresentado algum problema, a diversão, que é uma característica chave de jogos, foi alcançada. O jogo precisa ser divertido e prazeroso para o usuário, o que é uma das principais características de um jogo, como apontado anteriormente, e neste estudo o SolitaireQuiz atingiu esse objetivo.

Em relação ao entendimento do funcionamento e das regras do jogo, observou-se que a maioria dos idosos apresentou dificuldade em conhecer o jogo e depois jogá-lo sem dúvidas. Quando questionados sobre essa dificuldade, os participantes relataram que havia falta de tempo disponível para entender totalmente as regras do jogo antes de seu início. No entanto, a usabilidade de um jogo tem relação com a facilidade de uso e essa dificuldade, mesmo levando em consideração o tempo limitado que os usuários tiveram para jogar, isso mostra que a interface apresenta problemas em relação a esse item. Se houvesse uma boa usabilidade no jogo as regras seriam de fácil entendimento e os usuários conseguiriam transitar e utilizar o jogo intuitivamente.

Alguns participantes apontaram que deveria haver uma prévia do jogo para uma explicação maior sobre o mesmo. Mas essa prévia existe, ela está na forma de um vídeo no qual, antes de iniciar o jogo é possível clicar para assisti-lo, e conhecer as explicações gerais do jogo, as regras e como jogar. Dois participantes conseguiram ver este vídeo explicativo, porém, enfatizaram que ele deveria ser mais curto e didático. Além disso, durante o jogo existe a personagem "Vaqueira" que representa a ajuda do jogo, e uma vez que se passa o mouse sobre ela o menu de ajuda aparece sendo possível obter alguma informação, mas os participantes não foram proativos em clicar na "Vaqueira" para obter ajuda. Um fator apontado por todos os participantes foi a dificuldade de identificação dos números que aparecem nas cartas. Isso pode ter acontecido devido ao tamanho bem pequeno dos números exibidos nas cartas ou ao pouco contraste entre os elementos na tela usada para jogar. Isso mostra que a interface pode estar com problemas em seu layout, ou que o layout pode não ter sido pensado com as características necessária para o público alvo a que se destinava, contribuindo com a baixa usabilidade notada no jogo. À vista disso foi possível concluir que deve ser um item a ser reavaliado pelos criadores deste jogo.

Ao exercer o papel de pesquisadores estudando a aplicação de um jogo com idosos, emergiram reflexões importantes. Inicialmente percebeu-se que o fato de existir um cadastro inicial que deve ser realizado pelo participante e as escolhas prévias - como a escolha do assunto e nível, causava ansiedade nos participantes, pois não conseguiam iniciar logo o jogo. Sobre o cadastro inicial solicitado aos jogadores, nele é necessário inserir a inicial do nome do jogador, porém, se o nome for composto, o registro não é concluído e em nenhum momento o jogo avisa isso, ele apenas proíbe o jogador de prosseguir para a próxima tela do jogo. Essa peculiaridade só foi percebida após várias tentativas do participante, o que acabou gerando certo desânimo para iniciar o jogo, e o que se mostrou um grande erro que precisa de conserto urgente, pois impede o jogador até mesmo de iniciar o jogo.

Além dessas, outra observação feita durante a aplicação do jogo refere-se ao uso da "Vaqueira" como auxílio para a compreensão do jogo. Por meio dos relatos dos participantes, assim como das nossas observações, concluiu-se que as instruções da personagem passavam muito rapidamente, impossibilitando a leitura e compreensão dos idosos, resultando em outro aspecto não estimulante. Por fim, foi possível identificar que apenas um dos participantes, com histórico de utilizar várias horas do seu dia com jogos digitais, conseguiu finalizar e vencer o jogo, superando as dificuldades mencionadas acima.

Como sugestão para trabalhos futuros seria interessante perguntar ao próprio usuário idoso do SolitaireQuiz o que ele espera de um jogo desse gênero, e comparar com o que jogo aplicado durante esta pesquisa

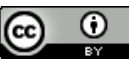


apresenta. Dessa forma tornar-se-á possível sugerir modificações para que o jogo atenda às expectativas do usuário, tornando-o, assim, mais atrativo e prazeroso. Além disso, poderia ser aplicada uma nova pesquisa com parâmetros similares, porém em outras regiões a fim de comparar as percepções de usuários com vivências sociais e culturais diferenciadas.

\section{Referências Bibliográficas}

AGE-WELL CONNECT. Age-well connect: Connecting older adults and caregivers to Canada's technology and aging community. Disponível em: https://agewell-nce.ca/training/age-well-connect-en. Acesso em 17 ago. 2020 .

ANSLEY, J.; ERBER, J. T. Computer Interaction: Effect on Attitudes and Performance in Older Adults. Educational Gerontology, 14(2): 107-19. 1988.

BRASIL. Lei 9.842, de 04 de janeiro de 1994. Política Nacional do Idoso. Disponível em: http://www.planalto.gov.br/ccivil_03/Leis/L8842.htm. Acesso em 17 ago. 2020.

BRASIL. Lei 10.741, de 1 de outubro de 2003. Estatuto do Idoso. Disponível em: http://www.planalto.gov.br/ccivil_03/LEIS/2003/L10.741.htm. Acesso em 17 ago. 2020.

BRITO, R. (2012). A utilização do computador e internet por idosos. Disponível em: http://ticeduca.ie.ul.pt/atas/pdf/358.pdf. Acesso em 17 ago. 2020.

BUIZA, C.; SOLDATOS, J.; PETSATODIS, T.; GEVEN, A.; ETXANIZ, A.; TSCHELIGI, M.. HERMES: Pervasive Computing and Cognitive Training for Ageing Well. Proceedings of the 10th International WorkConference on Artificial Neural Networks: Part II: Distributed Computing, Artificial Intelligence, Bioinformatics, Soft Computing, and Ambient Assisted Living. 2009, Salamanca, Spain, p. 756-763.

CAMARANO, A. A.. Envelhecimento da população brasileira: uma contribuição demográfica. In: FREITAS, E. V. de; PY, L.; NERI, A. L.; CANÇADO, F. A. X.; GORZONI, M. L.; ROCHA, S. M. da (Orgs.) Tratado de Geriatria e Gerontologia. 2.ed. Rio de Janeiro: Guanabara Koogan, 2002, p.88-105.

CARMO, Elisangela Gisele do. Envelhecimento e novas tecnologias: a inclusão digital e tecnológica na preparação para a aposentadoria e sua influência na qualidade de vida. 2016. 173 f. Dissertação (Mestrado) Curso de Ciências da Motricidade, Instituto de Biociências do Campus de Rio Claro, Universidade Estadual Paulista, Rio Claro, 2016. Disponível em: http://hdl.handle.net/11449/136183. Acesso em: 20 ago. 2020.

CHEN, T.; CHIANG, I.; LIU, E. Z.; CHANG, M. (2012). Effects of improvement on selective attention: Developing appropriate somatosensory video game interventions for institutional-dwelling elderly with disabilities. Turkish Online Journal of Educational Technology, v. 11, n. 4, p. 409-417, 2012.

CORDEIRO, J. R.; FADEL, L. M.. Jogos Digitais para Idosos: uma experiência de ensino. In: XIII SEMINÁRIO JOGOS ELETRÔNICOS, EDUCAÇÃO E COMUNICAÇÃO SJEEC, 18., 2019, Maceió/Alagoas. Anais... Maceió/Alagoas: ISBN: 2177 6989, p. 86 - 93.

COTA, T. T.; VIEIRA JUNIOR, N.; ISHITANI, L.. Impacto do gênero de jogo digital na motivação dos idosos para jogar. In: XIII SBGAMES, 8., 2014, Porto Alegre/RS. Proceedings... Porto Alegre/RS: SBGames, 2014. v. 1, p. 361 - 368. 
DE SCHUTTER, B.; ABEELE, V. V.. Designing meaningful play within the psycho-social context of older adults. In the 3rd International CFG. 2010.

FERREIRA, A.B.H.. Mini Dicionário Aurélio da Língua Portuguesa. 8.ed. Curitiba: Positivo, 2010,856 p.

FILIZOLA, M.; ROSE, L.."Será que ainda consigo?": a questão da acessibilidade do idoso na Internet. PUC/Rio. 2007. DAD. Disponível em: https://www.yumpu.com/pt/document/read/14841972/sera-que-aindaconsigo-marcela-filizola-e-luciana-de-rose. Acesso em 20 ago. 2020.

GIL, A. C. Métodos e técnicas de pesquisa social. 6. ed. São Paulo: Atlas, 2008.

GONÇALVES, V. P. . Um estudo sobre o design, a implementação e a avaliação de interfaces flexíveis para idosos em telefones celulares. Junho 2012. $171 \mathrm{f}$. Dissertação (Mestrado - Curso de Ciências de Computação e Matemática Computacional. Instituto de Ciências Matemáticas e de Computação, São CarlosSP, 2012.

HAYFLICK, L. Como e por que envelhecemos. Rio de Janeiro: Campus, 1996.

IBGE - Instituto Brasileiro de Geografia e Estatística. Brasil em síntese: Esperança de vida ao nascer (em anos) Brasil - 2000 a 2015. 2015. Disponível em:

http://brasilemsintese.ibge.gov.br/populacao/esperancas-de-vida-ao-nascer.html. Acesso em 20 ago. 2020.

MCMELLON, C.A.; SCHIFFMAN, L.G. . Cybersenior empowerment: how some older individuals are taking control of their lives. Journal of Applied Gerontology, 21, 157-175, 2002.

MENDOZA, G.A.; SAUVÉ, L.; PLANTE, P.. Adultos mayores y juegos educativos digitales. ¿Qué consideraciones de diseño favorecen su uso? EDUTEC, Revista electrónica de Tecnología Educativa, 62 , 2017.

NERI, A. L. (Org.). Idosos no Brasil: vivências, desafios e expectativas na terceira idade. São Paulo: Fundação Perseu Abramo, 2007.

NETI. (2020). Disponível em: https://neti.ufsc.br/. Acesso em 10 ago. 2020.

NIELSEN, J. . Usability Engineering. San Francisco: Morgan Kaufmann Publishers Inc, 1993.

OMS - Organização Mundial da Saúde. (2002). Envelhecimento ativo: uma política de saúde/World Health Organization. (S. Gontijo Trad.), Brasília: Organização Pan-Americana da Saúde. Disponível em: http://bvsms.saude.gov.br/bvs/publicacoes/envelhecimento_ativo.pdf. Acesso em 17 ago. 2020.

PAPALÉO NETTO, M.. O Estudo da Velhice: Histórico, Definição do Campo e Termos Básicos. In: FREITAS, Elizabete Viana. Tratado de Geriatria e Gerontologia. 2.ed. Rio de Janeiro: Guanabara Koogan, 2006.

PIRES, M. R. G. M.; GHUILHEM, D.; GOTTEMS, L. B. D.. Jogo (IN)DICA-SUS: estratégia lúdica na aprendizagem sobre o Sistema Único de Saúde. Texto \& Contexto - Enfermagem, v. 22, n. 2, p. 379-388, 2013.

PIROLA, A.R.; VELHO, A.P.M.; VERMELHO, S.C.S.D. (2012). Redes sociais na promoção da saúde do idoso: aspectos bibliográficos e de usabilidade. In: Mostra Interna de Trabalhos de Iniciação Científica, $6^{\mathrm{a}}$, 
2012, Maringá. Anais Eletrônico da VI Mostra Interna de Trabalhos de Iniciação Científica. Maringá: CESUMAR. 2012.

PORTO, C.F. Rezende, E.C.. Terceira idade, design universal e aging-inplace. Revista Estudos em Design. 2016.

PRODANOV, C. C.; FREITAS, E. C. de.. Metodologia do trabalho científico: métodos e técnicas de pesquisa e do trabalho acadêmico. 2. ed. Novo Hamburgo: Feevale, 2013.

ROCHA, Eron Moreno Chagas; PADOVANI, Stephania. Conduzindo Focus Group com Idosos: Compreendendo como Interagem e Querem Aprender a Utilizar Smartphones. Ergodesign \& Hci, Rio de Janeiro, v. 5, ano 5, núm. Especial, p. 36-48, 20 nov. 2017. Semestral. ISSN 2317-8876. Disponível em: http://periodicos.puc-rio.br/index.php/revistaergodesign-hci/article/view/353/324. Acesso em: 21 ago. 2020.

SALES, M. B. Desenvolvimento de um checklist para a avaliação de acessibilidade da web para usuários idosos. Dissertação de Mestrado - Universidade Federal de Santa Catarina, Centro Tecnológico. Programa de Pós-Graduação em Engenharia de Produção. 2002. 132 p.

SANTOS, L. G. N. de O.; ISHITANI, L.; NOBRE, C. N.. Uso de jogos casuais em celulares por idosos: um estudo de usabilidade. Revista de Informática Aplicada, v. 9, n. 1, p. 25-44, 2013.

TAMBASCIA, C. de A.; MELO, A. M.; PICCOLO, L. S. G.; ÁVILA, I. M. A. Usabilidade, acessibilidade e inteligibilidade aplicadas em interfaces para analfabetos, idosos e pessoas com deficiência. In: Proceedings of the VIII Brazilian Symposium on Human Factors in Computing Systems. Sociedade Brasileira de Computação, p. 354-355, 2008.

TOMPOROWSKI, P. D.. The Psychology of Skill: A lifespan approach. Westport, CT: Praeger Publishers, 2003.

VIANA, G. de S.; SALGADO, L. C. de C.; TREVISAN, D. G.. Usabilidade em Jogos em Diferentes Plataformas e Gêneros SBC - Proceedings of SBGames 2017 XVI SBGames - Curitiba - PR - Brazil, November 2nd - 4th, 2017 p. 158-164.

ZANELA, F. B.; BARTHOLO JUNIOR, R.; NAVEIRO, R. M.. Análise do uso de telefones celulares: o caso da população idosa. XXX Encontro Nacional de Engenharia de Produção: Maturidade e desafios da Engenharia de Produção: competitividade das empresas, condições de trabalho, meio ambiente. Anais... São Paulo, SP, 1-14, 2010.

ZIMMERMAN, E. Narrative, Interactivity, Play, and Games. In First Person: New Media as Story, Performance, and Game, Wardrip-Fruin, Noah and Harrigan, Pat, p. 154- 164. Cambridge MA, MIT Press, 2004.

\section{Agradecimentos}

As autoras agradecem ao NETI - Núcleo de Estudos da Terceira Idade pelo apoio recebido para o desenvolvimento deste trabalho.

Os resultados dessa pesquisa foram apresentados no X Jornadas Pedagógicas en Tecnología e Innovación Educativa - Universidad Casa Grande realizado na cidade de Guayaquil (Equador) nos dias 27, 28, 29 e 30 de novembro de 2019. 